\title{
Calcitonin gene-related peptide immunoreactivity and afferent receptive properties of dorsal root ganglion neurones in guinea-pigs
}

\author{
S. N. Lawson, B. Crepps ${ }^{*}$ and E. R. Perl ${ }^{*}$ \\ Department of Physiology, Medical School, University Walk, University of Bristol, Bristol BS8 1TD, UK and ${ }^{\star}$ Department of Cell $\lesssim$ Molecular \\ Physiology, University of North Carolina-CH, Chapel Hill, NC 27599 7545, USA
}

\begin{abstract}
To establish the afferent receptive properties of lumbosacral dorsal root ganglion (DRG) neurones that express calcitonin gene-related peptide (CGRP), intracellular recordings were made with fluorescent dye-filled electrodes in deeply anaesthetised young guinea-pigs. After determination of neuronal functional properties, dye was injected into the soma. CGRP-like immunoreactivity (CGRP-LI) was examined on histological sections of dye-marked neurones. Fourteen of $34 \mathrm{C}$-fibre neurones showed CGRP-LI. These included 10/21 C-fibre nociceptive neurones. All C-polymodal nociceptors in glabrous $(n=4)$ but none in hairy skin $(n=4)$ were positive. Positive C-fibre high threshold mechanoreceptive (HTM) units had receptive fields in dermal or deeper tissue. Four $(n=6)$ unresponsive or unidentified C-fibre units were positive. Neither C-fibre cooling sensitive $(n=4)$ nor C-fibre low threshold mechanoreceptive (LTM) units $(n=3)$ had CGRP-LI. Six of 23 A-fibre nociceptive cells were positive including one $A \alpha / \beta$ unit. Three of these positive cells had epidermal and three had dermal/deep receptive fields. Three of 36 A-fibre LTM units exhibited CGRP-LI; all were $A \alpha / \beta$-fibre $G$ hair units. All glabrous skin and muscle spindle units and in hairy skin slowly adapting and field units, and some G-hair units lacked CGRP-LI. CGRP-LI stained fibres were found in tissues containing receptive fields of positive DRG neurones: glabrous skin, near hair follicles and in skeletal muscle. A few substance P-labelled neurones did not exhibit CGRP-LI and vice versa. Thus CGRP expression was detected in under half the nociceptive neurones, was not limited to nociceptive neurones and apart from receptive properties was also related to location/depth in the tissues of a DRG neurone's peripheral terminals.
\end{abstract}

(Received 1 August 2001; accepted after revision 17 January 2002)

Corresponding author S. N. Lawson: Department of Physiology, School of Medical Sciences, University Walk, Bristol BS8 1TD, UK. Email: sally.Lawson@bristol.ac.uk

The peptide, calcitonin gene-related peptide (CGRP), is present in a substantial proportion of primary afferent neurones of many species (Lawson, 1992); however its relationship to afferent modalities is not well understood.

Calcitonin gene-related peptide release from peripheral terminals of primary afferent neurones contributes to local inflammatory responses, causing local vasodilatation and increasing the plasma extravasation produced by substance P (SP) (Gamse \& Saria, 1985; Brain \& Williams, 1989; Brain et al. 1992). It enhances leucocyte accumulation and margination (Buckley et al. 1991; Sung et al. 1992; Goebeler et al. 1994) and inhibits activity by Langerhans cells in epidermis (Hosoi et al. 1993).

Calcitonin gene-related peptide is reported to cause prolonged depolarisations in some dorsal horn neurones (Ryu et al. 1988a), and to facilitate persistence and spread of SP through the dorsal horn (Schaible et al. 1992). It has also been suggested to have a facilitatory effect on transmitter release and synaptic transmission in the dorsal horn (Oku et al. 1988; Ryu et al. 1988b). Detectable CGRP release in the dorsal horn occurs in response to noxious heat stimuli (Morton \& Hutchison, 1989). Therefore, CGRP appears to play a role in enhancing incoming signals in the dorsal horn.

In rat dorsal root ganglia (DRGs) CGRP-LI is present in all sizes of neuronal somata, including those with $\mathrm{C}, \mathrm{A} \delta$ and A $\alpha / \beta$ fibres (McCarthy \& Lawson, 1990). Its presence in large neurones and in $A \alpha / \beta$ neurones could be interpreted in two ways. It may be limited to nociceptive neurones since some of these have $A \alpha / \beta$ fibres (see Burgess \& Perl, 1967; Ritter \& Mendell, 1992, Djouhri et al. 1998) and relatively large cell bodies. Another possibility is that not all DRG neurones with CGRP-LI have nociceptive properties. There seems little doubt of CGRP expression within the nociceptive population, especially in view of its co-localisation with trkA (the high affinity nerve growth factor (NGF) receptor) (Averill et al. 1995; Fang et al. 
1999). However, a small number of high and low threshold mechanoreceptive (HTM and LTM, respectively) neurones with CGRP-LI have been described in rat DRGs (Hoheisel et al. 1994).

We undertook the present work to compare more closely the afferent signalling properties of individual DRG neurones with the expression of CGRP-LI. We also compared the CGRP-LI expression pattern with that of SP-LI (Lawson et al. 1997). The guinea-pig was chosen for these experiments because of the relative ease of making stable intracellular recordings from its C-fibre cells. Furthermore, the guinea-pig has a percentage of DRG profiles showing CGRP-LI that more closely resembles that of human DRGs than other rodents.

An abstract preliminarily describing some of the findings has appeared (Lawson et al. 1996a). Comparisons with previously published (Lawson et al. 1997) substance P-like immunoreactivity in the same neurones is made in Fig. 8.

\section{METHODS}

\section{Animal preparation}

One- to two-week-old guinea-pigs (weight 130-220 g; mean $180 \mathrm{~g}$ ) were anaesthetised with $50 \mathrm{mg} \mathrm{kg}^{-1}$ pentobarbital and the fur was clipped on the left hind limb. Tracheal and carotid artery cannulae were inserted and animals were ventilated artificially. End-tidal $\mathrm{CO}_{2}$ was monitored. Supplementary $10 \mathrm{mg} \mathrm{kg}^{-1}$ doses of pentobarbital were administered regularly via the intra-arterial cannula. Details of the preparation are given in Lawson et al. (1997). Briefly, a laminectomy from S2 to L1 exposed the left L5, L6 and S1 DRGs and their dorsal roots. Before recording from a DRG its dorsal root was cut at its entry into the spinal cord and laid over bipolar electrodes, which acted initially as recording electrodes to establish the receptive field area of the DRG, and then as stimulating electrodes during intracellular recording.

The animal was areflexic due to deep anaesthesia during the two hours prior to administration of a muscle relaxant (flaxedil). Before recording, flaxedil $\left(2 \mathrm{mg} \mathrm{kg}^{-1}\right)$ was administered I.V. with pentobarbital $\left(10 \mathrm{mg} \mathrm{kg}^{-1}\right)$. Supplementary flaxedil $\left(2 \mathrm{mg} \mathrm{kg}^{-1}\right)$ and anaesthetic $\left(10 \mathrm{mg} \mathrm{kg}^{-1}\right)$ were always administered together at regular intervals (approximately every hour) throughout the recording period. Failure of neuromuscular block could be detected by the reappearance of muscle contraction due to the spread of the electrical dorsal root search stimulus. Testing at such times showed the animal to be areflexic (no corneal or paw pinch withdrawal). In subsequent experiments using an identical anaesthetic regime, arterial blood pressure recording showed that arterial pressure did not rise between supplementary anaesthetic doses. In other experiments on the same preparation with the same anaesthetic regime but without a muscle relaxant, the animals remained deeply anaesthetised and areflexic throughout.

\section{Electrophysiological recording}

High impedance glass micropipettes filled with one of the following were used for the intracellular recordings: Lucifer Yellow CH (LY; $5 \mathrm{mg} \mathrm{ml}^{-1}$ ) in $0.1 \mathrm{M} \mathrm{LiCl}(200-570 \mathrm{M} \Omega$ ), and either cascade blue $(3 \% ; 160-500 \mathrm{M} \Omega$ ) or ethidium bromide (EB; $6 \mathrm{mM})$ in $1 \mathrm{~m} \mathrm{KCl}(60-150 \mathrm{M} \Omega)$. Recordings were from L6 and S1 DRGs in all animals and from L5 in a few animals.

\section{Conduction velocity}

The cut dorsal root was stimulated with a $0.3 \mathrm{~ms}$ voltage pulse. For A-fibre and C-fibre neurones, the pulse was adjusted to twice the threshold or suprathreshold, respectively, for evoking an action potential (AP) in the soma. The latency to the rise of the evoked AP with the distance from the locus of the dye-injected cell in the DRG to the stimulating cathode $(4-7.5 \mathrm{~mm})$ enabled calculation of the approximate dorsal root conduction velocity $(\mathrm{CV})$. The temperature of the liquid paraffin overlying the DRG was maintained between 28 and $30^{\circ} \mathrm{C}$. A $\alpha / \beta$ fibres conducted at $>4 \mathrm{~m} \mathrm{~s}^{-1}, \mathrm{~A} \delta$-fibres at $1-4 \mathrm{~m} \mathrm{~s}^{-1}$, and C-fibres at $<1 \mathrm{~m} \mathrm{~s}^{-1}$ as defined from compound action potential recordings in Lawson $e t$ al. (1997).

\section{Receptive field properties and locations}

The afferent signalling properties of each neurone were examined with hand-held stimulators following published classifications (Burgess \& Perl, 1967, 1973; Horch et al. 1977; Shea \& Perl, 1985) and as described in full previously (Lawson et al. 1997). Units with high mechanical thresholds were further defined by testing with sharp needles and fine and coarse forceps (Lawson et al. 1997) as superficial (probably epidermal or at the junction of the epidermis and dermis), dermal (including fat), or subcutaneous (when deep tissue, including muscle, needed to be involved to elicit a response). Although we cannot be certain of the exact depth of receptive terminals, for ease of communication, they are described as 'epidermal', 'dermal' and 'subcutaneous', respectively. Both Cand A-fibre units with high mechanical thresholds and superficial or dermal receptive fields were also tested for their response to noxious heat with a heated glass rod. Regions of the hind limb subjected to injurious stimulation were noted and subsequently avoided. A brief summary of how the units were classified is given below.

A-fibre units. These were separated into non-nociceptive or nociceptive categories; for details see Lawson et al. (1997). The non-nociceptive group included: D-hair units with A $\delta$ fibres, G-hair units consisting of subclasses G1 (very rapidly adapting to maintained hair displacement), or G2 (moderately rapidly adapting to hair movement). Field units were most effectively excited by direct skin disturbance and were classified similarly to G-hair units on the basis of their adaptation to skin displacement as F1 or F2. Slowly adapting (SA) glabrous skin units were classed as SAI (irregular discharge, not excited by skin stretch) or SAII (regularly discharging, sensitive to skin stretch), while hairy skin slowly adapting units were similarly classed as type I and type II. Additionally, glabrous skin, rapidly adapting (RA) units, vibration entrained (pacinian-like) units, and muscle-spindle (MS) units were recognised. Nociceptive A-fibre units included HTM (high threshold mechanoreceptive) and $\mathrm{MH}$ (mechano-heat) units. $\mathrm{MH}$ units were responsive to both needle pressure or pinch, and a single brief noxious heat stimulus. A-fibre HTM units included some moderate pressure units (Burgess \& Perl, 1967), and had superficial, usually distributed, punctate receptive fields and did not respond to a single noxious heat stimulus. Other HTM units had deeper receptive fields that were probably dermal or subcutaneous; these were grouped together because of the lack of difference in CGRP-LI.

C-fibre units. These were classified as $\mathrm{C}$ low threshold mechanoreceptive (C-LTM) units, as C-cooling or cold-sensitive, or as nociceptive units (Lawson et al. 1997). The nociceptive category was subdivided into $\mathrm{C}$ mechano-heat $(\mathrm{MH})$ units including C-fibre polymodal nociceptors (CPMs) with superficial receptive fields, and $\mathrm{C}-\mathrm{MH}$ units with sub-epidermal mechanical receptive 
fields. The CPMs were further subdivided into glabrous (G-CPM) and hairy (H-CPM) skin units. The adequate stimulus for $\mathrm{C}$ high threshold mechanoreceptive (C-HTM) units was pinch or squeeze; these units had no response to noxious heat. One unit was excited by noxious heat but not by intense mechanical stimuli and was classed as a $\mathrm{C}$ heat nociceptor.

\section{Intracellular dye injection}

After establishment of receptive properties, fluorescent dye was electrophoretically injected into the soma. LY 0.6-1.5 nA (usually $0.6 \mathrm{nA}$ ) rectangular $500 \mathrm{~ms}$ negative pulses at $1 \mathrm{~Hz}$ for up to $5 \mathrm{~min}$; EB (0.3-1 nA) and cascade blue (1.2-1.5 nA) were injected with positive current pulses. The membrane potential was checked every 30 s. during dye injection. For further details see (Stefanini et al. 1967; Lawson et al. 1997).

The animal was killed under deep anaesthesia, by terminal perfusion through the carotid cannula with $0.9 \%$ saline followed by Zamboni's fixative (see Lawson et al. 1997).

\section{Tissue preparation}

The DRGs from which recordings had been made were postfixed for approximately $1 \mathrm{~h}$ in Zamboni's fixative and stored overnight in $30 \%$ sucrose buffer at $4{ }^{\circ} \mathrm{C}$. Serial $7 \mu \mathrm{m}$ cryostat sections of the DRGs were placed on at least 10 gelatin/chrom alum-coated slides, so that each slide had every tenth section on it. The dyelabelled neurones were located using fluorescence microscopy and their positions in the DRG checked against experimental records. The position of each section through a dye-labelled neurone was recorded with camera lucida drawings, to enable relocation of the cell later after immunocytochemistry. Sections were stored at $-20^{\circ} \mathrm{C}$ until used for immunocytochemistry. Sections through the edge of the soma were not used for immunocytochemistry unless, in a very small cell, they were adjacent to the section containing the nucleus.

\section{Immunocytochemistry}

Endogenous biotin or biotin-like activity was blocked using an Avidin/biotin blocking kit (Vector SP-2001) Avidin-Biotin immunocytochemistry was carried out with a Vectastain Elite $\mathrm{ABC}$ kit (Vector Laboratories, Burlingame, CA, USA) (rabbit IgG, Vector PK-6101), with the addition of $0.3 \%$ Triton X-100 to washes, antibody and $\mathrm{ABC}$ steps. The primary polyclonal anti-CGRP antibody raised in rabbit against human CGRP (Peninsula laboratories) was diluted at 1:4000-1:8000 in Tris-buffered saline containing $0.3 \%$ Triton $\mathrm{X}-100$. The sections were incubated in this solution at $4{ }^{\circ} \mathrm{C}$ for $15-25 \mathrm{~h}$ prior to completion of the $\mathrm{ABC}$ processing to produce a $\mathrm{DAB}$ (diamino benzidine) brown reaction product (Lawson et al. 1997). Preabsorption tests on the primary antibody showed complete loss of immunoreactivity on this tissue when the antibody had been preabsorbed overnight at $4{ }^{\circ} \mathrm{C}$ with $10^{-6}-10^{-7}$ M CGRP.

The relative intensity of immunoreactivity was compared for CGRP-LI and for substance P-LI (SP-LI) in sections of the same neurones (Lawson et al. 1997). A rabbit polyclonal antibody was used for SP-LI (Incstar 20064, Incstar Corporation, Stillwater, MN, USA; dilution at 1:4000:8000). Otherwise methods were the same as for CGRP immunocytochemistry.

\section{Assessment of the immunocytochemical reaction product}

The intensity of the immunocytochemical staining of the dyeinjected neurone was scored in comparison to the intensity of staining of other neurones in the same region of the same DRG section, as: negative (clearly unlabelled, score 0 ) or positive (clearly labelled, score $>1$ ). Positive cells were scored from 1 (weakly, but unambiguously positive) to 5 (as intense, as the most intensely stained profile in that tissue section).

The relative intensities of SP-LI published previously (Lawson et al. 1997) were compared with those for CGRP-LI where these had both been examined on the same neurone. They had been scored
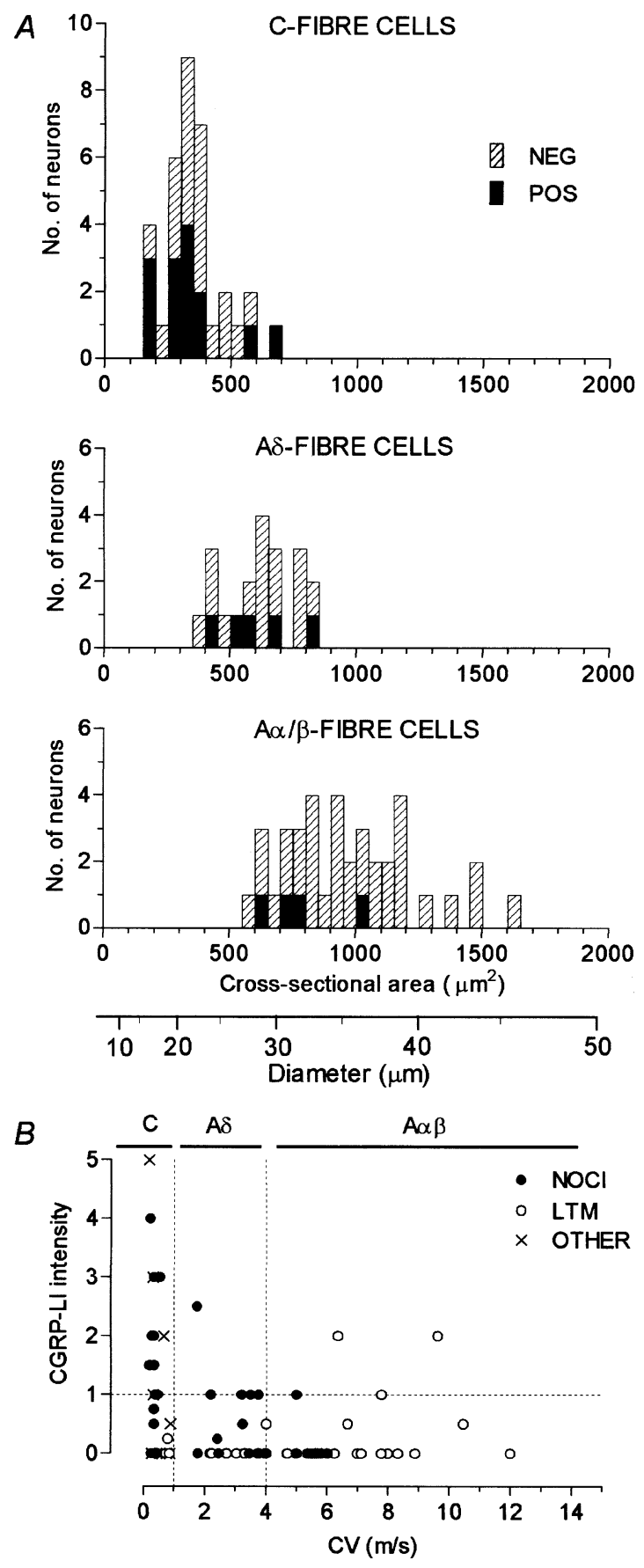

Figure 1. Cell size and conduction velocity in relation to CGRP-LI

$A$, distribution of sizes of the largest section through each dyelabelled neurone. Separate plots of C-, A $\delta$ - and $A \alpha / \beta$-fibre neurones are shown. The CGRP-LI positive units are shown as filled bars. The positive G-hair units were the three largest positive $\mathrm{A} \alpha / \beta$-fibre units. Below $A$ is a scale converting area to diameter. $B$, dorsal root $C V$ of the dye-labelled cell is plotted against the relative intensity score for CGRP-LI. 

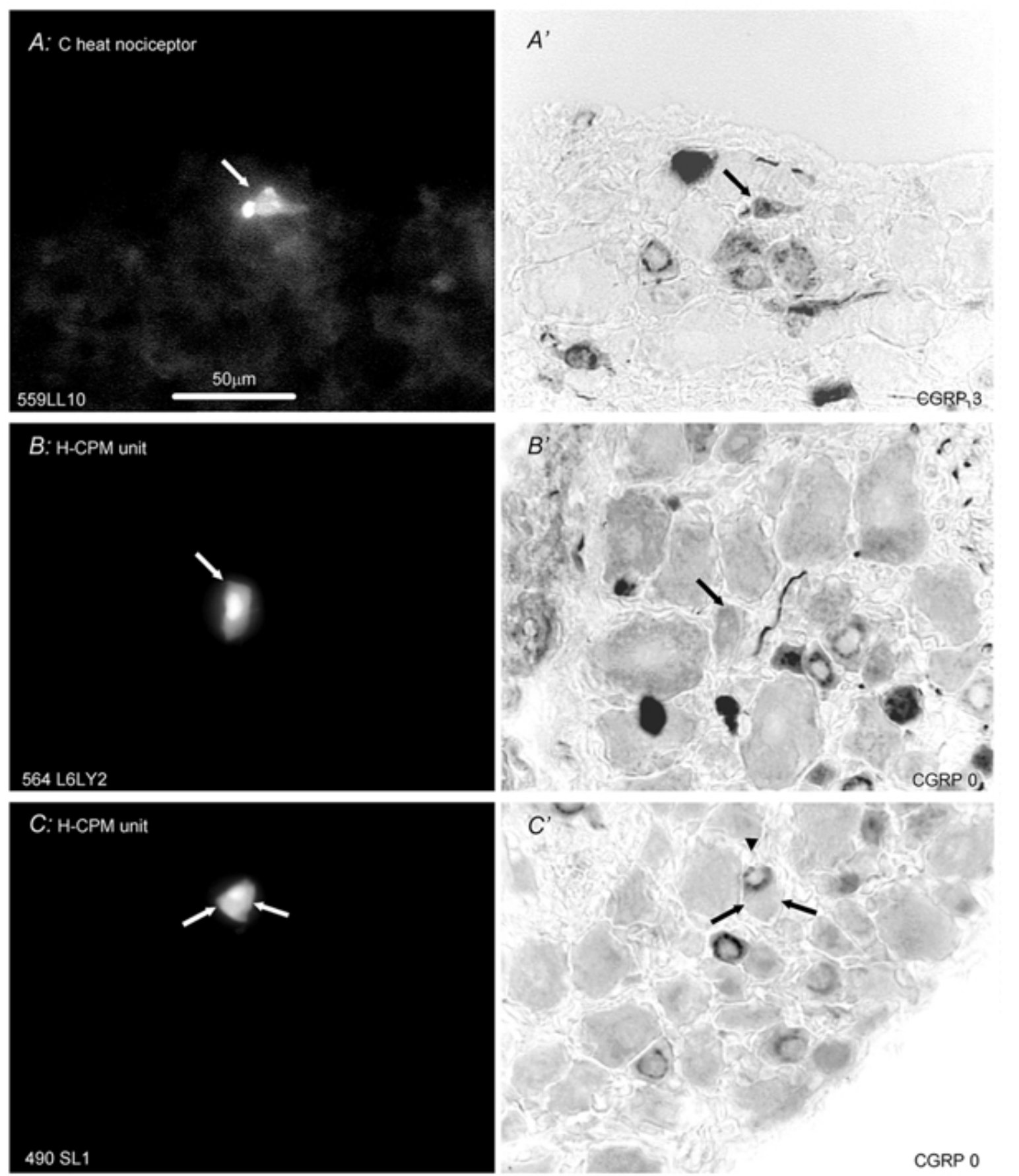

$D: C$ cool sensitive
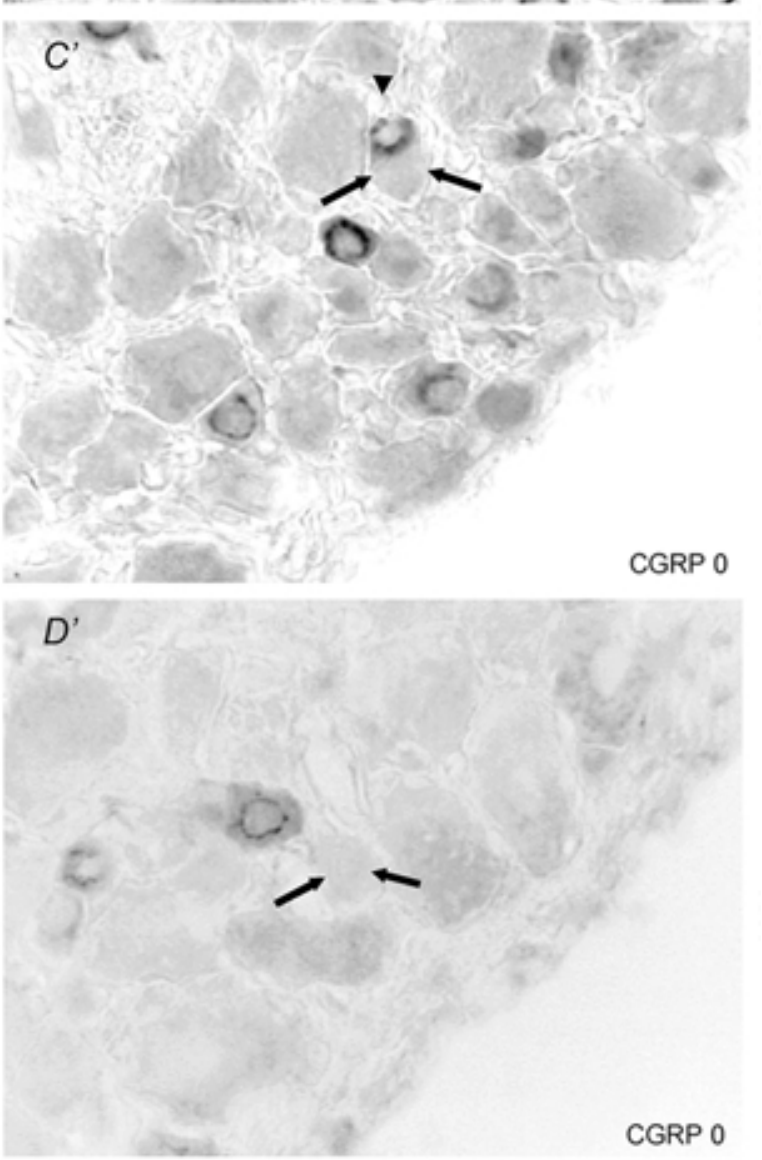

CGRP 0

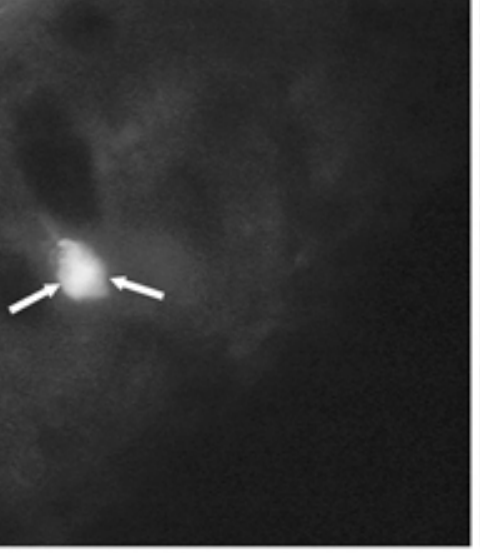

Figure 2. For legend see facing page. 
as above and calculated using image analysis methods as previously described (Lawson et al. 1997); each neurone of interest was given a percentage relative intensity rating by comparing the SP-LI intensity of that neurone with unlabelled ( $0 \%$ intensity) neurones and the most intensely labelled (100\% intensity) neurones in that section. Using this method, neurones with a relative intensity of $20 \%$ (equivalent to 1 for the CGRP rating scheme) or more were considered to be labelled (Lawson et al. 1997).

\section{Technical problems}

The necessary precautions outlined in a previous study (Lawson et al. 1997), were adhered to in the present study. Briefly, the size and duration of current passed to inject dye into the soma were kept to a minimum to reduce the likelihood that the peptide content or immunoreactivity might be affected. If locations of dye-labelled neurones did not match records of location made during recording, those cells were excluded from the analyses. Sections through the edge of a neurone were not used, in case they did not include the immunostained region of the cytoplasm. The proportions and size distributions of rat DRG neurones expressing CGRP have previously been shown to be unaffected by the intracellular presence of the dyes LY and EB (McCarthy \& Lawson, 1990, Lawson et al. 1996b).

All experiments were conducted with the approval of the Institutional Animal Care and Use Committee of the University of North Carolina at Chapel Hill.

\section{RESULTS}

Of 93 dye-injected neurones tested, 23 (25\%) were judged to be positive for CGRP-LI. This compares favourably with the mean percentage of CGRP-LI labelled profiles in the control ganglia of about 30\% (range about 25-35\%; $n=5$; number of cells counted per DRG, 250-490), particularly given the likely bias in the electrophysiological studies towards larger neurones, few of which show CGRP-LI.

Subdivided according to $\mathrm{CV}$, the dye-labelled neurones with CGRP-LI included 14/34 (41\%) C-fibre units, 5/20 (25\%) A $\delta$-fibre neurones and 4/39 (10\%) A $\alpha / \beta$-fibre neurones. Nine of $59(15 \%)$ of all A-fibre units were positive. The size distributions of the CGRP-LI positive and negative dye-injected neurones are shown in Fig. $1 A$. There was overlap in the size distributions of the C-, A $\delta$ and $A \alpha / \beta$-fibre units, although the mean soma sizes for all neurones as well as for neurones that showed CGRP-LI were in the order $A \alpha / \beta>A \delta>C$. The largest CGRP-LI positive neurones were amongst the more rapidly conducting units and their size did not exceed $1000 \mu \mathrm{m}^{2}$.

The most intense CGRP-LI was found in the smallest neurones as was reported for rat DRGs (e.g. McCarthy \& Lawson, 1990). Figure $1 B$ shows that the most intensely labelled neurones were the more slowly conducting $\mathrm{C}$ - and A $\delta$-fibre units. The three positive G-hair units were relatively lightly labelled and had CVs in the middle of the A $\alpha / \beta$-fibre range.

Figure 2 shows micrographs of sections containing identified C-fibre neurones labelled with LY before, and after CGRP immunocytochemistry. The intense immunoreactivity in the probable C-heat nociceptor (Fig. $2 A$ ) is in sharp contrast with the lack of staining in C-polymodal nociceptors with receptive fields in hairy skin (Fig. $2 B$ and $C$ ) and in a C-cooling unit (Fig. 2D).

Figure 3 presents examples of CGRP-LI in A $\delta$-fibre neurones. The absence of staining in A $\delta$ HTMs with superficial receptive fields (Fig. $3 A$ ) differs distinctly from the positive CGRP-LI staining of an $\mathrm{A} \delta \cdot \mathrm{MH}$ unit (Fig. $3 B$ ). A CGRP-LI negative D-hair (A $\delta$-fibre) unit is also shown (C). Figure 4 shows examples of the labelling of $A \alpha / \beta$-fibre units: a negative HTM with a superficial receptive field (Fig. 4A), a negative hairy skin type II mechanoreceptor (Fig. $4 B$ ), a positive G-hair neurone exhibiting mottled CGRP-LI (Fig. $4 C$ ), and a negative A $\alpha / \beta$-fibre (field) LTM unit (Fig. 4D).

\section{Receptive properties of C-fibre units with CGRP-LI}

Figure 5 presents graphs plotting the relative intensity of CGRP-LI in relation to afferent receptive properties. All positive units with identified signalling properties were nociceptive (NOCI, Fig. 5A, Table 1). The few cooling/cold receptors and the C-LTM cells were negative. A high proportion (4/6) of the units grouped as miscellaneous (MISC) gave positive staining (Fig. 5A and inset, Table 1). This group included five unresponsive units that could not be activated by noxious mechanical stimuli, radiant warming, or cooling. They were not tested with noxious

\section{Figure 2. CGRP-LI in identified C-fibre neurones}

Left column $(A-D)$ shows fluorescence images prior to immunocytochemistry of Lucifer Yellow (LY) dyeinjected neurones; right column shows images of the same neuronal section after immunocytochemistry for CGRP-LI. Cells $A, B$ and $D$ are from L6 and $C$ is from $S 1$. The CVs of the units were $\left(\mathrm{m} \mathrm{s}^{-1}\right) A, 0.35 ; B, 0.36$; $C, 0.37$ and $D, 0.76$. $A$, section though a C-fibre heat nociceptor that responded to noxious heat but not innocuous radiant heat on the foot. No mechanically sensitive region could be found. Although this section is through the edge of the cell, it is adjacent to one containing the nucleus in this very small cell. $B$ and $C$ present two examples of CGRP-LI negative H-CPMs (hairy skin C-polymodal nociceptors) with receptive fields on the upper leg/thigh. $C$, strongly positive unit (arrowhead in $C^{\prime}$ ) is just above negative units (shown with two arrows). $D$, cooling/cold sensitive neurone with spontaneous discharge at room temperature that was promptly inhibited by radiant warming of the sole of the foot. Scale bar in $A$ applies to all images. The subjectively judged scores of CGRP-LI relative intensity are given at the bottom right of each image showing CGRP-LI. 
heat; however, two positive cells of the unresponsive group were spontaneously active with an irregular, slow bursting, discharge. Pressure on the lower abdomen increased the background discharge of one of these, suggesting that they may have been visceral afferent units. One unresponsive unit without spontaneous activity also showed CGRP-LI.
Nociceptive C-fibre units showing CGRP-LI (Fig. 5B, Table 1) had either sub-epithelial (dermal or subcutaneous) or glabrous skin CPM (G-CPM) receptive fields. The superficial (probably epidermal) HTMs and the hairy-skin CPMs (H-CPMs) were CGRP-LI negative. The only positive superficial units were the G-CPMs. The most
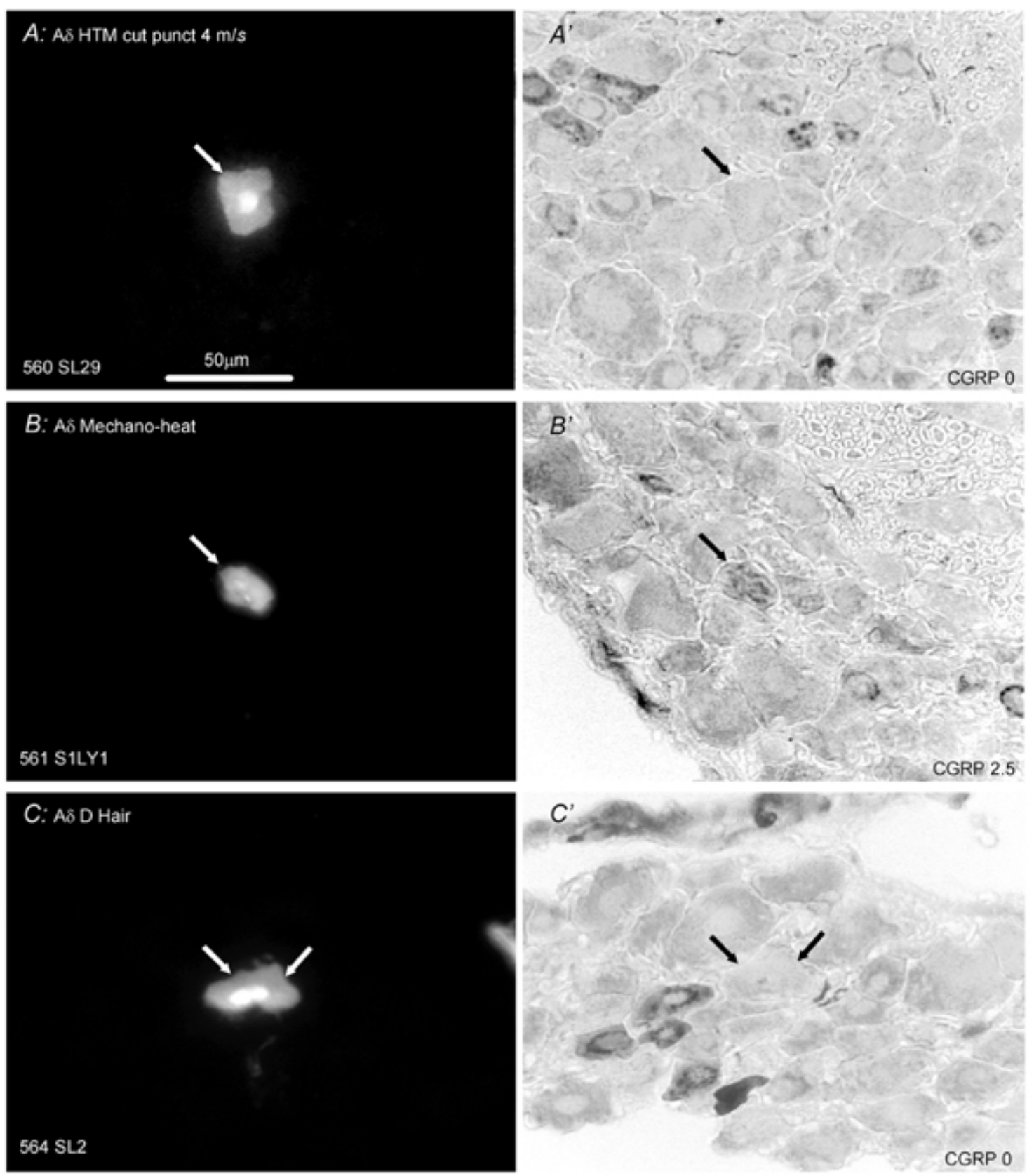

Figure 3. CGRP-LI in identified A $\delta$-fibre neurones

Layout as in Fig. 2. Left, S1 DRG neurones labelled with LY; right, micrographs of the same DRG sections processed to show CGRP-LI. A, CGRP-LI negative HTM that had a typical superficial, distributed punctate receptive field $\left(\mathrm{CV}, 4 \mathrm{~m} \mathrm{~s}^{-1}\right)$. B, MH cell (mechanical-heat nociceptor) $\left(\mathrm{CV}, 1.8 \mathrm{~m} \mathrm{~s}^{-1}\right.$ ) that was unambiguously positive for CGRP-LI. The receptive field was superficial and punctate on the side of the upper leg, evoking a response to pressure with needle, pinch by fine forceps and noxious heat. $C$, section through the nucleus of a D-hair unit $\left(\mathrm{CV}, 3.1 \mathrm{~m} \mathrm{~s}^{-1}\right)$ that was negative for CGRP-LI. The unit had a receptive field on the thigh that gave vigorous responses to moving brush, skin stretch and sudden cooling. Scale bar in $A$ applicable to all. 

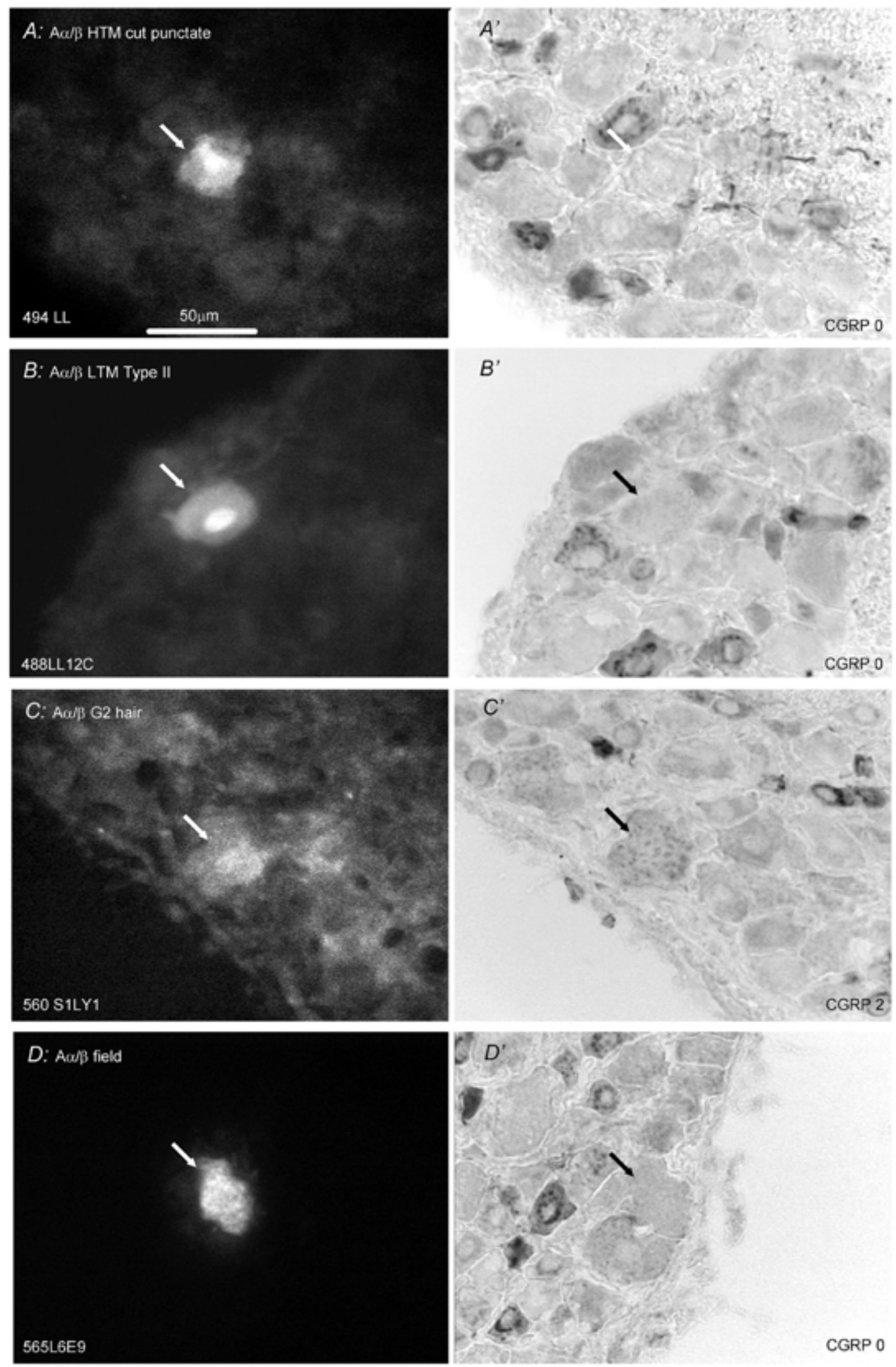

CGRP 0

\section{Figure 4. CGRP-LI in identified $A \alpha / \beta$-fibre neurones}

Format as for Fig. 2. In $A, B$ and $C$, the labelling fluorescent dye was LY and in $D$ was ethidium bromide. $A$ and $B$ are from L6, $C$ is from $S 1$ and $D$ is from L5. $A, B$ and $C$ are through the cell nuclei, whereas $D$ is through the cytoplasm $A, \mathrm{~A} \alpha / \beta \mathrm{HTM}\left(\mathrm{CV}, 5.5 \mathrm{~m} \mathrm{~s}^{-1}\right)$ with a superficial punctate receptive field negative for CGRP-LI. $B$, a slowly adapting type II unit $\left(\mathrm{CV}, 5.6 \mathrm{~m} \mathrm{~s}^{-1}\right)$ with receptive field on the thigh negative for CGRP. C, G2 hair unit $\left(\mathrm{CV}, 9.6 \mathrm{~m} \mathrm{~s}^{-1}\right)$ with receptive field at the top of the thigh showed mottled cytoplasmic CGRP-LI labelling. $D$, field unit $\left(\mathrm{CV}, 6.3 \mathrm{~m} \mathrm{~s}^{-1}\right)$ negative for CGRP-LI with receptive field on the dorsal surface of a toe. Scale bar in $A$ applicable to all. 
Table1. Sensory receptive properties of neurones with CGRP-LI

\begin{tabular}{|c|c|c|c|}
\hline Sensory receptor classification & Receptive region & $\begin{array}{l}\text { CGRP-LI } \\
\text { pos/total }\end{array}$ & $\%$ \\
\hline \multicolumn{2}{|l|}{ All C-fibre nociceptive units } & $10 / 21$ & 48 \\
\hline \multicolumn{4}{|l|}{ Superficial $\quad$ C polymodal $(\mathrm{CPM})$} \\
\hline ........ H-CPM & Hairy skin, foot and leg & $0 / 4$ & \\
\hline ........ G-CPM & Glabrous skin, foot and toes & $4 / 4$ & \\
\hline Superficial C-HTM & Hairy and glabrous & $0 / 3$ & \\
\hline Dermal C-HTM & Dermis/fat/fascia & $3 / 3$ & \\
\hline Subcutaneous C-HTM & Muscle/joint/deep fascia & $2 / 6$ & \\
\hline Heat nociceptor (probable) & Foot & $1 / 1$ & \\
\hline C-LTM & Superficial/thigh & $0 / 3$ & \\
\hline C cooling & Not known & $0 / 4$ & \\
\hline C Miscellaneous: all & & $4 / 6$ & 67 \\
\hline Unresponsive spontaneous & None found, possibly visceral & $2 / 2$ & \\
\hline Unresponsive not spontaneous & None found & $1 / 3$ & \\
\hline Untested & & $1 / 1$ & \\
\hline \multicolumn{2}{|l|}{ All C-fibre units } & $14 / 34$ & 41 \\
\hline A $\delta$ Nociceptive units: all & & $5 / 12$ & 42 \\
\hline Superficial HTM & 2 (negative) glabrous/5 hairy & $1 / 7$ & \\
\hline Superficial & Knee/upper leg & $2 / 2$ & \\
\hline Superficial $\quad \mathrm{MH}$ glabrous & Heel pad & $0 / 1$ & \\
\hline Dermal or subcutaneous & Leg/heel & $2 / 2$ & \\
\hline A $\delta$ LTM D-hair units & 6 upper leg/ 1 foot $/ 1$ ankle & $0 / 8$ & $\mathbf{0}$ \\
\hline All A $\delta$ units & & $5 / 20$ & 25 \\
\hline $\mathrm{A} \alpha / \beta$ nociceptive units: all & & $1 / 11$ & 9 \\
\hline Superficial HTM & 4 foot/1 knee/1 flank & $0 / 6$ & \\
\hline Superficial MH & Glabrous on foot & $0 / 2$ & \\
\hline Dermal or subcutaneous & Leg & $1 / 3$ & \\
\hline $\mathrm{A} \alpha / \beta$ cutaneous units: all & & $3 / 20$ & 15 \\
\hline Field (2 F2, 3 F1 and1 F intermediate units) & Dorsal foot/thigh & $0 / 6$ & \\
\hline G hair (4 G2 and $2 \mathrm{G}$ /intermediate units) & Foot/ankle/thigh & $3 / 6$ & \\
\hline Slowly adapting (SA II OR Type II) & Thigh/toe & $0 / 3$ & \\
\hline Rapidly adapting ( 3 glabrous RA and 2 Pacinian) & Glabrous RAs: Sole of foot & $0 / 5$ & \\
\hline $\begin{array}{l}\text { A } \alpha / \beta \text { LTM muscle spindle units } \\
\quad \text { (4 type I and } 4 \text { type II units) }\end{array}$ & Foot/lower leg/upper leg & $0 / 8$ & 0 \\
\hline All $A \alpha / \beta$ units & & $4 / 39$ & 10 \\
\hline All neurones examined & & $23 / 93$ & 25 \\
\hline
\end{tabular}

intense CGRP-LI was exhibited by some of the HTM units with subepidermal receptive fields and the lone heat nociceptor exhibited CGRP-LI.

\section{Receptive properties of A-fibre units with CGRP-LI}

Twenty-five percent (6/23) of the A-fibre nociceptors and about $10 \%$ of $A \alpha / \beta$-fibre LTMs (3/28) had CGRP-LI (Table 1, Fig. 6).

Most A-fibre nociceptive units had distributed punctate superficial receptive fields and were typical myelinated fibre, cutaneous HTM units. The proportion of A $\delta$-fibre nociceptors displaying CGRP-LI was higher than for $\mathrm{A} \alpha / \beta$-fibre nociceptors (Table 1, Fig. 6). Only A $\delta$-fibre units classified as nociceptors had detectable CGRP-LI; these positive units included $3 / 17$ with superficial and $3 / 5$ with dermal or deep receptive fields (Fig. $6 B$ ). The only positive $A \alpha / \beta$ nociceptive unit was one of three $A \alpha / \beta$
HTMs with a dermal or subcutaneous receptive field (Fig. 6B). Thus, as for C-fibre units, A-fibre nociceptors with dermal or subcutaneous receptive fields were more likely to be positive than those with epidermal receptive fields. Of the three positive units with superficial receptive fields, a higher proportion of MH than of HTM units were positive (2/4 MH and 1/13 HTM). Only one positive A $\delta$ HTM had a superficial field in hairy skin.

Most A-fibre LTMs (A $\delta$ D-hair units, A $\alpha / \beta$ field units $(n=7)$, RA $(n=5)$ and SA $(n=3)$, and muscle spindle afferent units $(n=8))$ did not express CGRP-LI (Fig. $6 \mathrm{~A}$ and $C$ ); however, 3/6 G2-hair units were positive for CGRP-LI (Table 1).

To put our observations on afferent neurones into perspective, we felt it important to examine the putative receptive tissues in the guinea-pig for nerve fibres exhibiting 
CGRP-LI. Figure 7 shows examples of staining for CGRP-LI in skin and muscle. Fibres can be seen closely associated with hair follicles (Fig. $7 A$ and $B$ ), and in relationship to skeletal muscle fibres (Fig. 7C). In glabrous skin, CGRP-LI positive fibres were found within the dermis and dermal papillae, apparently penetrating the epithelium (Fig. 7D). CGRP-LI-labelled fibres also appeared at the border of the epidermis and dermis (Fig. 7E), and in association with subcutaneous adipose tissue (Fig. 7F).

\section{Comparison of labelling intensities for SP-LI and CGRP-LI}

In most neurones there was a tendency for the relative intensities of CGRP-LI and SP-LI to be fairly closely parallel; however there were exceptions (Fig. 8). Five CGRP-LI positive units did not show SP-LI; these were three C-fibre nociceptors (a G-CPM with a marked response to noxious
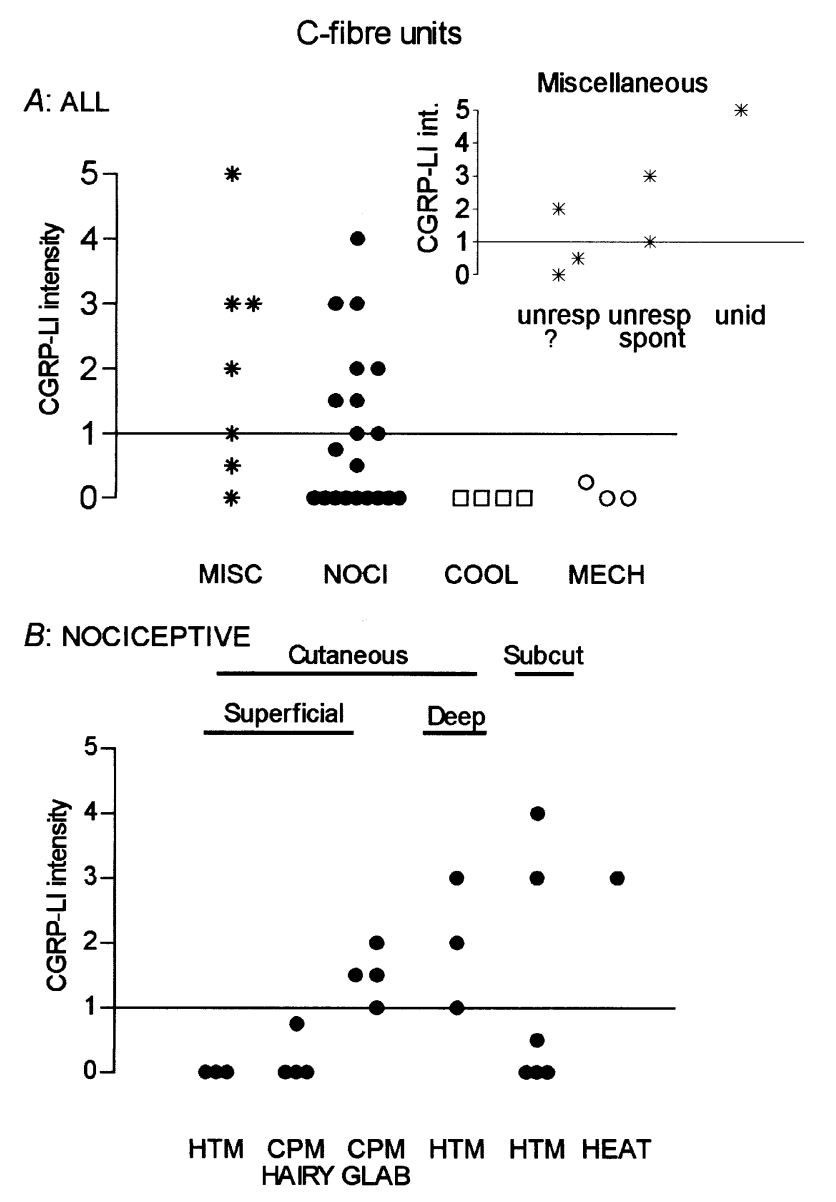

Figure 5. C-fibre units: intensities of CGRP-LI in relation to afferent receptive properties

$A$, plot of all units studied. The miscellaneous group (MISC) contained unresponsive or unidentified neurones (see text). $B$, the nociceptive $\mathrm{C}$-fibre neurones are subdivided according to their responses to noxious mechanical and noxious heat stimuli, and to the apparent depth in the tissues of their receptive fields. Abbreviations as follows: $\mathrm{NOCl}$, nociceptive; COOL, cooling sensitive; $\mathrm{MECH}, \mathrm{C}$ mechanoreceptor (C LTM); unresp, unresponsive; unid, unidentified. heat and two C-HTMs with subcutaneous receptive fields), and two A $\alpha / \beta$ fibre G2-hair neurones. Three units were positive for SP-LI but not for CGRP-LI; they were two C-fibre nociceptors (a C-HTM with a subcutaneous receptive field and a C-HTM with a superficial receptive field) and an $\mathrm{A} \delta$-fibre nociceptor unit with a distributed punctate receptive field.
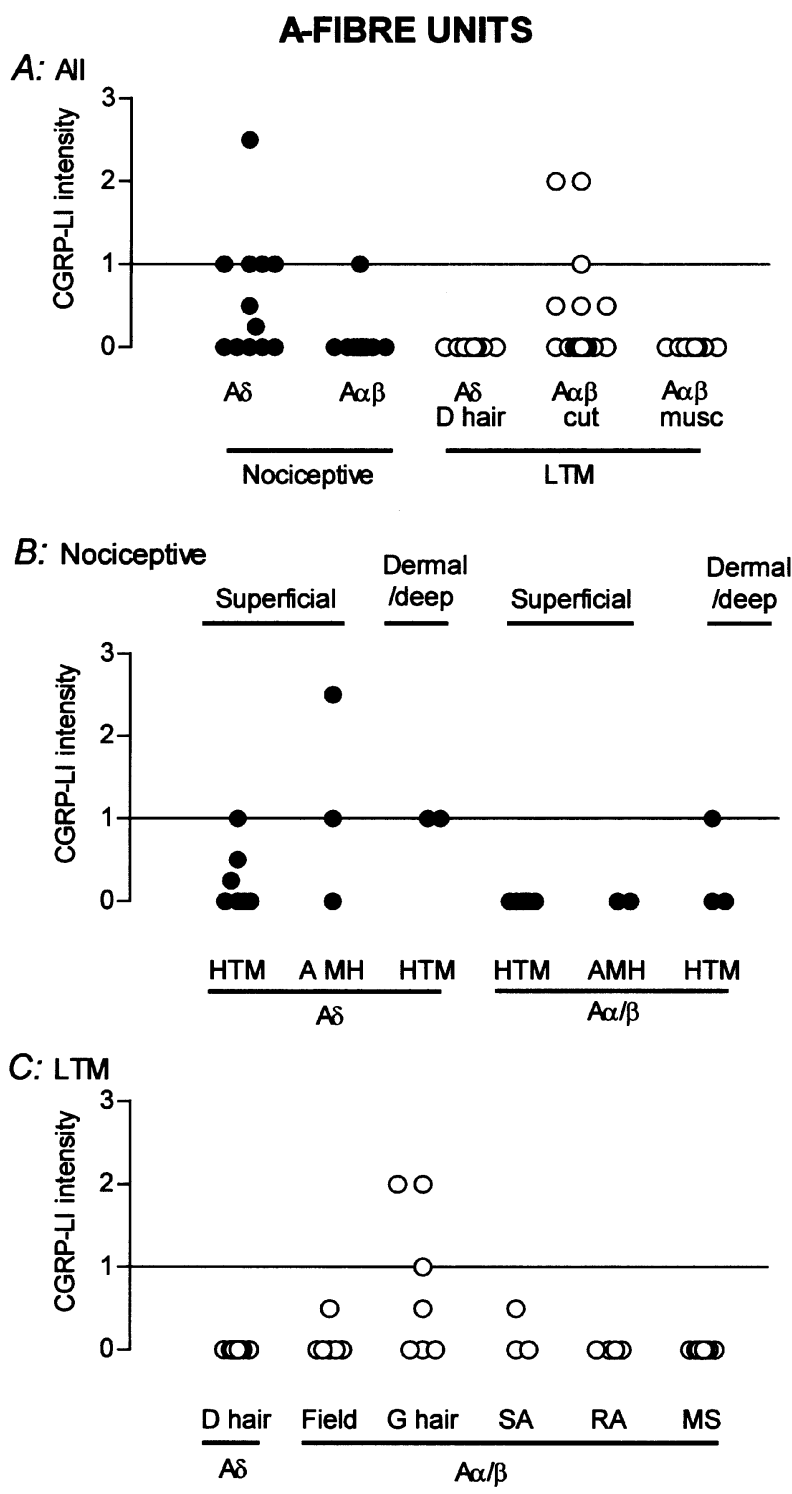

Figure 6. A-fibre units: intensities of CGRP-LI in relation to afferent receptive properties

$A$, nociceptive and LTM units subdivided into $\mathrm{A} \alpha / \beta$ and $\mathrm{A} \delta$ groups. A $\alpha / \beta$ cutaneous LTM (cut) and muscle spindle (musc) units shown separately. A subgroup of nociceptors and certain $A \alpha / \beta$ LTM units were positive. $B$, the nociceptive $A \delta$ - and $\mathrm{A} \alpha / \beta$-units are separated into those with superficial (probably epidermal) and subepidermal (dermal/deep) receptive fields. Units with superficial fields were divided according to their response to noxious heat into HTM and MH units. $C$, A-fibre LTMs subdivided according to receptive type. SA, slowly adapting LTM; RA, rapidly adapting LTM ; MS, muscle spindle LTM units. Note: none of the $A \delta$-fibre (D hair) category were positive and G-hair receptors were the sole $A \alpha / \beta$ units expressing CGRP-LI. 

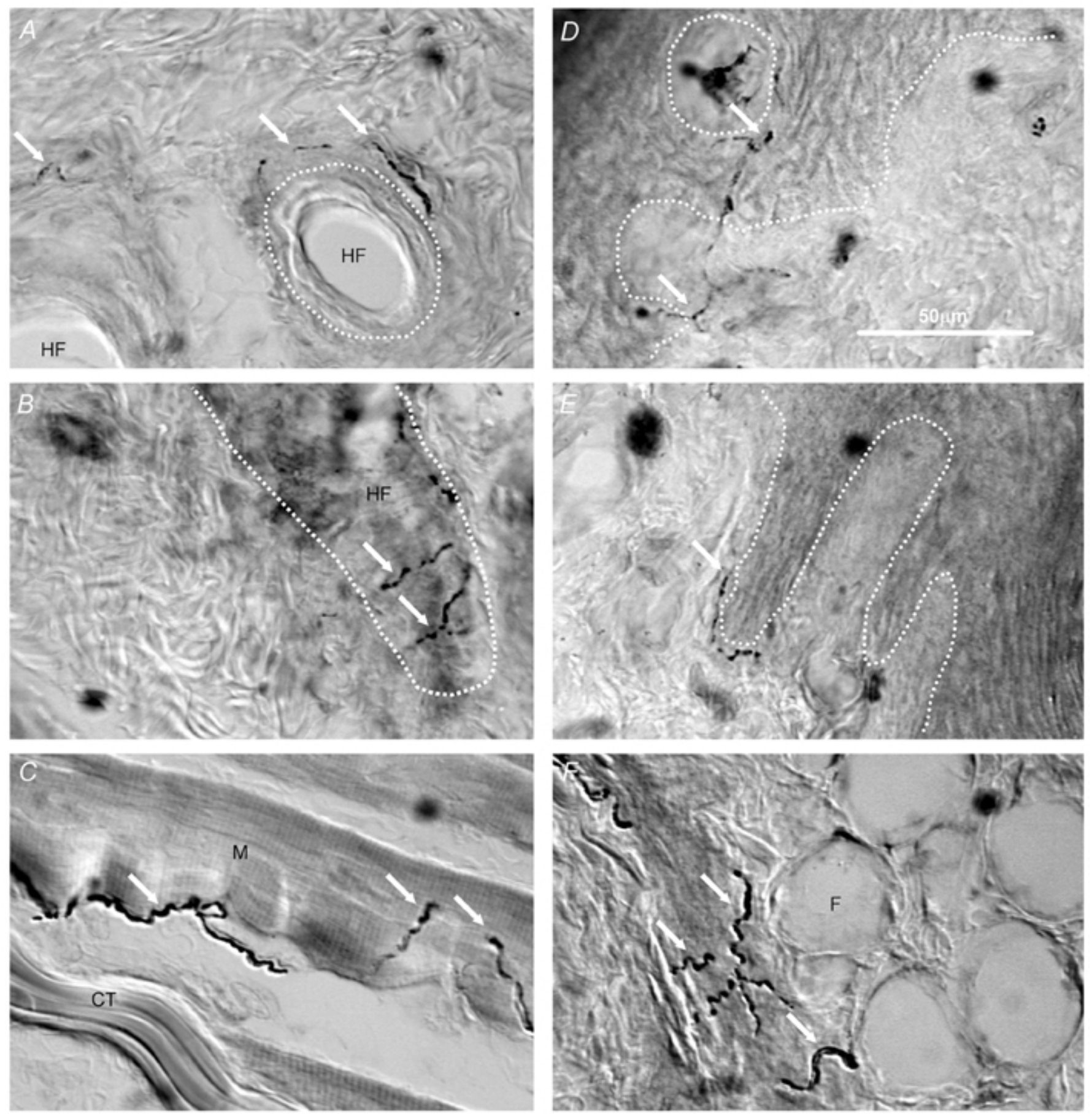

Figure 7. CGRP-LI in nerve fibres of guinea-pig skin and muscle

Images captured using interference contrast microscopy to show CGRP-LI-labelled nerve fibres in hairy skin $(A$ and $B)$, skeletal muscle $(C)$ and glabrous skin $(D, E$ and $F$ ). Some CGRP-LI-labelled nerve fibres are indicated by white arrows. $A$ and $B$, the approximate outlines of hair follicles are indicated with white dotted lines showing CGRP-LI-positive fibres to be associated with hair follicles. C, CGRP-LI positive fibres are present in skeletal muscle. $D$ and $E$, the junction between the epidermis and dermis is indicated with the white dotted line. $D$, the white dotted circle outlines a dermal projection into the epidermis (dermal papilla). CGRP-LI-positive fibres can be seen within dermal pegs and apparently penetrating the epidermis, as well as $(E)$ at the junction between dermis and epidermis. $F$, fat cells under the foot pad with positive fibres (arrows). CT, connective tissue; $\mathrm{M}$, skeletal muscle fibre; HF, hair follicle; F, fat cell. Scale bar in $D$ is for all images. 


\section{DISCUSSION}

This study documents that CGRP-LI in DRG neurones: (a) appeared in less than half of a sample of nociceptive neurones and (b) was not limited to nociceptive neurones. Furthermore, among nociceptors, the presence of CGRP-LI appeared to be related to receptive tissue and effective stimuli. The proportion of HTM units with CGRP-LI was higher in those with receptive fields located in non-superficial (dermal or subcutaneous) tissues. For nociceptors with superficial receptive fields, a higher proportion of those that responded to both mechanical and heat stimuli showed CGRP-LI than those that were only mechanoreceptive. The probability of somata expressing CGRP-LI was greater for G-CPMs (glabrous skin $\mathrm{CPMs}$ ) than for $\mathrm{H}-\mathrm{CPMs}$ (hairy skin CPMs).

The distribution in guinea-pig of fibres with CGRP-LI in peripheral tissues is consistent with the locations of receptive fields of CGRP-LI-positive DRG neurones. Fibres in the dermis and in the sub-epidermal tissue (including dermis, fatty tissue and skeletal muscle) may be those of CGRP-expressing nociceptive units with dermal or deeper receptive fields. Some of the sparse fibres penetrating the epidermis and/or those at the epidermal/dermal junction could be those of CGRP- expressing units with superficial receptive fields, most likely CPMs or $\mathrm{A} \delta$-MH units. Similar patterns of fibres with CGRP-LI have been described in both rat and human skin (Terenghi et al. 1993; Suh \& Eun, 1995). The latter report mentions occasional CGRP-LI fibres penetrating the epidermis but emphasises that there is a greater abundance at the epidermal-dermal border and within the dermis. Our observation of CGRP-LI positive hair-follicle afferent DRG neurones (G hair) is consistent with the close association of CGRP-LI fibres with hair follicles in guinea-pig skin. A similar pattern, although with more abundant CGRP-LI fibres, is described for rat skin (Kruger et al. 1989; Lawson, 1996); lanceolate hair follicle-associated endings from $A \alpha / \beta$ fibres show CGRP-LI (Rice et al. 1997). Since CGRP-LI fibres associated with hair follicles have also been described in human skin (Dalsgaard et al. 1989) it seems likely that CGRP is present in the equivalent of G-hair afferent units in human skin as well. Interestingly, increased CGRP levels resulted in increased human hair follicle length in vitro (Suh \& Eun, 1995), suggesting a possible trophic role for peripherally released CGRP.

The present observation of CGRP in A-fibre LTM units is consistent with reports in rat DRGs of: (a) a few LTM neurones with CGRP-LI (Hoheisel et al. 1994) and (b) the presence of CGRP-LI in a few A $\alpha / \beta$-fibre neurones that had short duration action potentials and after-hyperpolarisations typical of A-LTM neurones (Lawson et al. 1996b).

It is not surprising that the two probable visceral afferent units were CGRP positive, since retrograde labelling studies in rat found that most $(70 \%$ of bladder or $99 \%$ of splanchnic) visceral afferent DRG somata express CGRP-LI (Bennett et al. 1996; Perry \& Lawson, 1998).

Differences in the proportion of DRG neuronal profiles with detectable CGRP-LI exist between different mammalian species. The largest percentage is reported for the rat (from 30 to $60 \%$ ) while for several other species the value is about $30 \%$ (cat, adult human and guinea-pig) (S. Border, personal communication; Lawson, 1992). The greater fraction of $A \alpha / \beta$-fibre DRG neurones with unambiguously detectable CGRP-LI in the rat (17-20\%, McCarthy \& Lawson, 1990; Lawson et al. 1996b) compared with $10 \%$ in the guinea-pig (present study), suggests the possibility that in the rat, A-LTM neurones other than hair-follicle afferents may express detectable CGRP-LI. Consonant with this, in the rat, CGRP-LI has been reported in the terminations of fibres associated with Meissner's corpuscles but not in their parent axons; CGRP has also been described in unmyelinated fibres that make up part of the Meissner corpuscle complex (IshidaYamamoto et al. 1988; Garcia-Caballero et al. 1989; Rice et al. 1997; Johansson et al. 1999). CGRP-LI was, however, not detected in our three guinea-pig $A \alpha / \beta$-fibre glabrous RA units, a type of afferent unit attributed to encapsulated endings/Meissner corpuscles (Jänig, 1971). The only previous study to examine CGRP-LI in identified DRG neurones was in the rat (Hoheisel et al. 1994); two

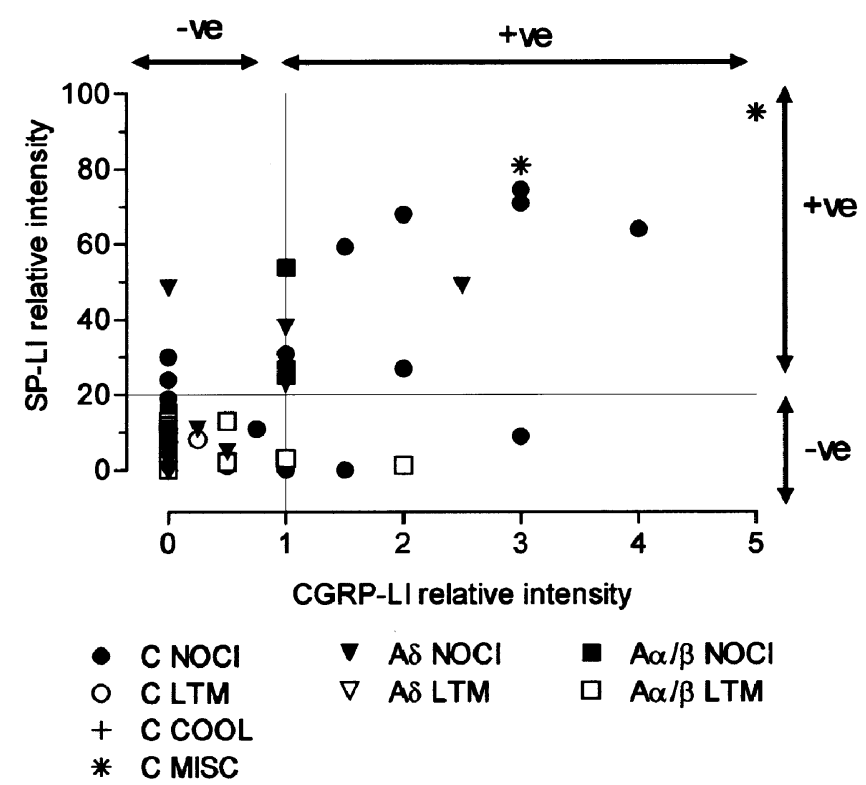

Figure 8. Relative intensities of CGRP-LI and SP-LI in the same DRG somata

See Methods for generation of relative intensity measurements on $x$ and $y$ axes. For SP-LI, the values are calculated using image analysis measurements, with $100 \%$ representing maximum intensity and $\geqslant 20 \%$ relative intensity judged as positive. For CGRP-LI, 5 was maximum and values $\geqslant 1$ were judged as positive. For abbreviations, see Fig. 5 legend. 
LTM A $\alpha / \beta$ units with CGRP-LI were a hair-follicle unit and a muscle-spindle afferent unit. The present study confirms the former in the guinea-pig but not the latter.

The patterns of CGRP-LI in the present study raise questions about the function of CGRP. The role of peripherally released CGRP in increasing local blood flow and enhancing peripheral inflammatory responses is well established (see above). It is often assumed that the peripheral release of CGRP is from nociceptive neurones in response to noxious stimulation of the tissues. If the CGRP-LI that is detectable in the soma provides an indication of that available for release in the periphery, our results suggest a greater likelihood of peripheral release of CGRP from CPMs or A-MH units terminating superficially in glabrous than in hairy skin. In the case of mechanical nociceptive units, those with receptive fields in dermal or subcutaneous tissue would be more likely to release CGRP than those in epidermal tissue. Afferent endings in thick glabrous epidermis protected by a thick keratin layer, or in sub-epidermal tissue, are better insulated from external stimulation than those in the relatively thin hairy skin epidermis. In this light, one could rationalize the more frequent expression of CGRP by nociceptive DRG neurones with peripheral terminals in glabrous skin and sub-epidermal tissues than in the epidermis of hairy skin by the probability that stimuli exciting glabrous or deep nociceptive endings are more likely to result in serious tissue damage. Limitation of damage and its repair would benefit from vasodilatation and other inflammationrelated changes. However, in the above proposal, CGRP serves a primary nociceptive-related function. While that concept might fit much of the data on distribution of the peptide in DRG neurones supplying somatic tissue, it does not account for its presence in a select set of cutaneous LTM units and in a very large proportion of visceral afferent fibres (Perry \& Lawson, 1998).

A less teleological approach would assume that the peripheral function of CGRP in primary afferent fibres is to mediate local vasodilatation on their activation, thereby playing a protective/nutritive role. In this scheme, CGRP is most likely to be present in DRG neurones supplying heavily vascularised regions (e.g. dermis, subdermal fat and muscle). This concept could also rationalise the presence of CGRP in the myelinated DRG neurones of LTMs such as G2-hair follicle or Meissner corpuscle units as well as in nociceptors.

CGRP released centrally from primary afferent neurones may increase excitability in some neurones of the spinal dorsal horn, perhaps by potentiating the release of SP or the effects of released SP ( Oku et al. 1987; Schaible et al. 1992) thereby contributing to sensitisation of the central nociceptive pathway. A $\beta$-hair follicle afferent arbors are found in laminae IV and III and even project into the inner part of lamina II (see review by Fyffe, 1992). Fibres with
CGRP-LI in the dorsal horn terminate mainly in laminae I, II and V, but are also scattered in the laminae in between them (Carlton et al. 1987; Carlton et al. 1988). This is consistent with a majority of CGRP fibres being nociceptive and a minority being LTM. The present data therefore raise the possibility that some large diameter LTM neurones may be capable of releasing CGRP centrally; low levels of release from these afferent fibres may have been undetectable with the techniques used to date. CGRP release from LTM units could therefore conceivably contribute to changes in excitability of central systems involved in sensations other than pain.

In summary, CGRP-LI was found in less than half the population of nociceptive DRG neurones, with a preponderance of positive units in cells with more slowly conducting fibres. The proportion of positive units was related to the category of the nociceptive units and to the location and depth of their receptive fields in peripheral tissues. CGRP-LI was also found in some A $\alpha / \beta$-LTM units raising issues about possible functions of peripherally and centrally released CGRP from these units.

\section{REFERENCES}

Averill, S., Mcmahon, S. B., Clary, D. O., Reichardt, L. F. \& Priestley, J. V. (1995). Immunocytochemical localization of trkA receptors in chemically identified subgroups of adult rat sensory neurons. European Journal of Neuroscience 7, 1484-1494.

Bennett, D. L., Dmietrieva, N., Priestley, J. V., Clary, D. \& McMahon, S. B. (1996). TrkA, CGRP and IB4 expression in retrogradely labelled cutaneous and visceral primary sensory neurones in the rat. Neuroscience Letters 206, 33-36.

Brain, S. D., Cambridge, H., Hughes, S. R. \& Wilsoncroft, P. (1992). Evidence that calcitonin gene-related peptide contributes to inflammation in the skin and joint. Annals of the New York Academy of Sciences 657, 412-419.

Brain, S. D. \& Williams, T. J. (1989). Interactions between the tachykinins and calcitonin gene-related peptide lead to the modulation of oedema formation and blood flow in rat skin. British Journal of Pharmacology 97, 77-82.

Buckley, T. L., Brain, S. D., Rampart, M. \& Williams, T. J. (1991). Time-dependent synergistic interactions between the vasodilator neuropeptide, calcitonin gene-related peptide (CGRP) and mediators of inflammation. British Journal of Pharmacology 103, 1515-1519.

Burgess, P. R. \& PerL, E. R. (1967). Myelinated afferent fibres responding specifically to noxious stimulation of the skin. Journal of Physiology 190, 541-562.

Burgess, P. R. \& Perl, E. R. (1973). Cutaneous mechanoreceptors and nociceptors. In Somatosensory System, vol. 2: Handbook of Sensory Physiology, ed. A. Iggo, pp. 29-78. Springer-Verlag, Berlin.

Carlton, S. M., Mcneill, D. L., Chung, K. \& Coggeshall, R. E. (1987). A light and electron microscopic level analysis of calcitonin gene-related peptide (CGRP) in the spinal cord of the primate: an immunohistochemical study. Neuroscience Letters. 82, 145-150.

Carlton, S. M., Mcneill, D. L., Chung, K. \& Coggeshall, R. E. (1988). Organization of calcitonin gene-related peptideimmunoreactive terminals in the primate dorsal horn. Journal of Comparative Neurology 276, 527-536. 
Dalsgaard, C.-J., Jernbeck, J., Stains, W., KJartansson, J., Haegerstrand, A., Hökfelt, T., Brodin, E., Cuello, A. C. \& Brown, J. C. (1989). Calcitonin gene-related peptide-like immunoreactivity in nerve fibers in the human skin. Relation to fibers containing substance $\mathrm{P}$-, somatostatin- and vasoactive intestinal polypeptide-like immunoreactivity. Histochemistry $\mathbf{9 1}$, 35-38.

Djouhri, L., Bleazard, L. \& Lawson, S. N. (1998). Association of somatic action potential shape with sensory receptive properties in guinea-pig dorsal root ganglion neurons. Journal of Physiology 513, 857-872.

FanG, X., Djouhri, L., \& Lawson, S. N. (1999). Sensory receptor type and electrophysiological properties of A-fiber dorsal root ganglion (DRG) neurones that express trkA in the rat. Society for Neuroscience Abstracts 25, 1946.

FyfFe, R. E. W. (1992). Laminar organisation of primary afferent terminations in the mammalian spinal cord. In Sensory Neurones: Diversity, Development and Plasticity, ed. Scotr, S. A. pp. 131-139. Oxford University Press, New York.

GAmse, R. \& SARIA, A. (1985). Potentiation of tachykinin induced plasma protein extravasation by calcitonin gene-related peptide. European Journal of Pharmacology 114, 61-66.

Garcia-Caballero, T., Gallego, R., Roson, E., Fraga, M. \& BeIras, A. (1989). Calcitonin gene-related peptide (CGRP) immunoreactivity in the neuroendocrine Merkel cells and nerve fibres of pig and human skin. Histochemistry 92, 127-132.

Goebeler, M., Henseleit, U., Roth, J. \& Sorg, C. (1994). Substance $\mathrm{P}$ and calcitonin gene-related peptide modulate leukocyte infiltration to mouse skin during allergic contact dermatitis. Archives of Dermatological Research 286, 341-346.

Hoheisel, U., Mense, S. \& Scherotzke, R. (1994). Calcitonin generelated peptide immunoreactivity in functionally identified primary afferent neurones in the rat. Anatomy and Embryology 189, 41-49.

Horch, K. W., Tuckett, R. P. \& Burgess, P. R. (1977). A key to the classification of cutaneous mechanoreceptors. Journal of Investigative Dermatology 69, 75-82.

Hosoi, J., Murphy, G. F., Egan, C. L., Lerner, E. A., Grabbe, S., Asahina, A. \& Granstein, R. D. (1993). Regulation of Langerhans cell function by nerves containing calcitonin generelated peptide. Nature 363, 159-163.

IshidA-Yамамото, A., Senba, E., \& Tонyama, M. (1988). Calcitonin gene-related peptide- and substance P-immunoreactive nerve fibers in Meissner's corpuscles of rats: An immunohistochemical analysis. Brain Research 453, 362-366.

JäNIG, W. (1971). Morphology of rapidly and slowly adapting mechanoreceptors in the hairless skin of the cat's hind foot. Brain Research 28, 217-231.

Johansson, O., FAntini, F. \& Hu, H. (1999). Neuronal structural proteins, transmitters, transmitter enzymes and neuropeptides in human Meissner's corpuscles: a reappraisal using immunohistochemistry. Archives of Dermatological Research. 291, 419-424.

Kruger, L., Silverman, J. D., Mantyh, P. W., Sternini, C. \& Brecha, N. C. (1989). Peripheral patterns of calcitonin-generelated peptide general somatic sensory innervation: cutaneous and deep terminations. Journal of Comparative Neurology 280, 291-302.

LAwson, S. N. (1992). Morphological and biochemical cell types of sensory neurones. In Sensory Neurones: Diversity, Development and Plasticity, ed. Scotт, S. A., pp. 27-59. Oxford University Press, New York.
LAwson, S. N. (1996). Neurochemistry of cutaneous nociceptors. In Neurobiology of Nociceptors, ed. Belmonte, C. \& Cervero,C., pp. 72-91. Oxford University Press, Oxford.

Lawson, S. N., Crepps, B., Buck, H. \& Perl, E. R. (1996a). Correlation of CGRP-like immunoreactivity (CGRP-LI) with sensory receptor properties in dorsal root ganglion (DRG) neurones in guinea pigs. Journal of Physiology 493, 45P.

Lawson, S. N., Crepps, B. A. \& Perl, E. R.(1997). Correlation of Substance P-like immunoreactivity with sensory receptor type in guinea-pig primary afferent neurones. Journal of Physiology 505, 177-191.

Lawson, S. N., McCarthy, P. W. \& Prabhakar, E. (1996b). Electrophysiological properties of neurones with CGRP-like immunoreactivity in rat dorsal root ganglia. Journal of Comparative Neurology 365, 355-366.

McCarthy, P. W. \& Lawson, S. N. (1990). Cell type and conduction velocity of rat primary sensory neurons with calcitonin generelated peptide-like immunoreactivity. Neuroscience 34, 623-632.

Morton, C. R. \& Hutchison, W. D. (1989). Release of sensory neuropeptides in the spinal cord: studies with calcitonin generelated peptide and galanin. Neuroscience 31, 807-815.

Oku, R., Nanayama, T. \& SaToh, M. (1988). Calcitonin gene-related peptide modulates calcium mobilization in synaptosomes of rat spinal dorsal horn. Brain Research 475, 356-360.

OKu, R., SатоH, M., FujiI, N., Отака, A., Yajima, H. \& Takagi, H. (1987). Calcitonin gene-related peptide promotes mechanical nociception by potentiating release of substance $\mathrm{P}$ from the spinal dorsal horn in rats. Brain Research 403, 350-354.

Perry, M. J. \& Lawson, S. N. (1998). Differences in expression of oligosaccharides, neuropeptides, carbonic anhydrase and neurofilament in rat primary afferent neurones retrogradely labelled via skin, muscle or visceral nerves. Neuroscience $\mathbf{8 5}$, 293-310.

Rice, F. L., Fundin, B. T., Arvidsson, J., Aldskogius, H. \& Johansson, O. (1997). Comprehensive immunofluorescence and lectin binding analysis of vibrissal follicle sinus complex innervation in the mystacial pad of the rat. Journal of Comparative Neurology 385, 149-184.

Ritter, A. M. \& Mendell, L. M. (1992). Somal membrane properties of physiologically identified sensory neurons in the rat: Effects of nerve growth factor. Journal of Neurophysiology 68, 2033-2041.

Ryu, P. D., Gerber, G., Murase, K. \& Randic, M. (1988a). Actions of calcitonin gene-related peptide on rat spinal dorsal horn neurons. Brain Research 441, 357-361.

Ryu, P. D., Gerber, G., Murase, K. \& Randic, M. (1988b). Calcitonin gene-related peptide enhances calcium current of rat dorsal root ganglion neurons and spinal excitatory synaptic transmission. Neuroscience Letters 89, 305-312.

Schaible, H. G., Hope, P. J., Lang, C. W. \& Duggan, A. W. (1992). Calcitonin gene-related peptide causes intraspinal spreading of substance P released by peripheral stimulation. European Journal of Neuroscience 4, 750-757.

SheA, V. K. \& PerL, E. R. (1985). Sensory receptors with unmyelinated $(\mathrm{C})$ fibers innervating the skin of the rabbit's ear. Journal of Neurophysiology 54, 491-501.

Stefanini, M., De Martino, C. \& Zamboni, L. (1967). Fixation of ejaculated spermatozoa for electron microscopy. Nature 216, 173-175.

Sun, D. H. \& Eun, H. C. (1995). The effect of calcitonin gene-related peptide on hair growth in vitro. Annals of Dermatology 7, 308-312. 
Sung, C.-P., Arleth, A. J., Aiyar, N., Bhatnagar, P. K., Lysko, P. G. \& Feuerstein, G. (1992). CGRP stimulates the adhesion of leukocytes to vascular endothelial cells. Peptides 13, 429-434.

Terenghi, G., Sundaresan, M., Moscoso, G. \& Polak, J. M. (1993). Neuropeptides and a neuronal marker in cutaneous innervation during human foetal development. Journal of Comparative Neurology 328, 595-603.

\section{Acknowledgements}

This work was supported by a grant from the MRC, UK to S. N. L and for most of the experimental work by grant NS 10321 from the NINDS of the United States NIH to E. R. P. We are grateful to J. Bao, H. Buck and B. W. Brighton for technical assistance and to S. Joseph for help with the manuscript. 